\title{
Platelet-Mediated Protection of Cancer Cells From Immune Surveillance - Possible Implications for Cancer Immunotherapy
}

\section{OPEN ACCESS}

Edited by:

Dimitrios Mougiakakos, University of Erlangen

Nuremberg, Germany

Reviewed by: Lisa Sevenich

Georg Speyer Haus, Germany Rodabe N. Amaria, University of Texas MD Anderson

Cancer Center, United States

*Correspondence: Stephan Meinke stephan.meinke@ki.se

Specialty section

This article was submitted to Cancer Immunity and Immunotherapy,

a section of the journal

Frontiers in Immunology

Received: 11 December 2020 Accepted: 09 February 2021 Published: 10 March 2021

Citation:

Schmied L, Höglund P and Meinke S (2021) Platelet-Mediated Protection of Cancer Cells From Immune

Surveillance - Possible Implications for Cancer Immunotherapy. Front. Immunol. 12:640578. doi: 10.3389/fimmu.2021.640578

\section{Laurent Schmied, Petter Höglund and Stephan Meinke*}

Department of Medicine Huddinge, Center for Hematology and Regenerative Medicine, Karolinska Institutet, Huddinge, Sweden

The growing insights in the complex interactions between metastatic cancer-cells and platelets have revealed that platelet tumor cell interactions in the blood stream are an important factor supporting tumor metastasis. An increased coagulability of platelets facilitates the vascular evasion and establishment of solid tumor metastasis. Furthermore, platelets can support an immunosuppressive tumor microenvironment or shield tumor cells directly from engagement of cytotoxic lymphocytes as e.g., natural killer (NK) cells. Platelets are both in the tumor microenvironment and systemically the quantitatively most important source of TGF- $\beta$, which is a key cytokine for immunosuppression in the tumor microenvironment. If similar platelet-tumor interactions are of physiological relevance in hematological malignancies remains less well-studied. This might be important, as T- and NK cell mediated graft vs. leukemia effects (GVL) are well-documented and malignant hematological cells have a high exposure to platelets compared to solid tumors. As NK cell-based immunotherapies gain increasing attention as a therapeutic option for patients suffering from hematological and other malignancies, we review the known interactions between platelets and NK cells in the solid tumor setting and discuss how these could also apply to hematological cancers. We furthermore explore the possible implications for NK cell therapy in patients with solid tumors and patients who depend on frequent platelet transfusions. As platelets have a protective and supportive effect on cancer cells, the impact of platelet transfusion on immunotherapy and the combination of immunotherapy with platelet inhibitors needs to be evaluated.

Keywords: NK cells, platelets, immunosuppressive, tumor microenvironment, antitumor immunity, metastasis, immunotherapy, cytotoxicity

\section{INTRODUCTION}

Natural killer (NK) cells represent the largest fraction of innate lymphocytes, accounting for $10-15 \%$ of all peripheral lymphocytes in humans $(1,2)$, The physiological importance of NK cells is commonly ascribed to their capability to form early responses against viral infections and malignant cells (3). The main effector functions of NK cells encompass elimination of cells identified as targets, along with the secretion of proinflammatory cytokines, which can attract further immune cells and thereby promote the formation of an adaptive immune response (4). NK cell activation is regulated by the integration 
of signals from an array of different germline-encoded activating and inhibitory receptors (5). Activating receptors on NK cells bind many stress-induced ligands as for example MICA and MICB, which are recognized by NKG2D on NK cells (6). The main inhibitory receptors are the killer cell immunoglobulin like receptors (KIR) which bind to HLA class I and NKG2A which binds to HLA-E, thereby allowing NK cells to kill virally infected or transformed cells that escape $\mathrm{T}$ cell-mediated immunosurveillance by down-regulation of $\operatorname{HLA}(3,7,8)$. This unique capability of immediate cytotoxicity toward malignant and virally infected cells makes NK cells attractive for antitumor therapy approaches (9). Especially since a clinically relevant antitumor effect has been described before, when a NK cell-mediated graft vs. leukemia effect $(\mathrm{GvL})$ was found after haploidentical hematopoietic stem cell transplantation (HSCT), in case of HLA mismatch when NK cell tolerance is broken $(10,11)$. Currently, different anti-tumor therapies rely on tumor cell lysis through cytotoxic lymphocytes, mainly NK- and T cells. This includes beside NK- and T-cell-mediated GvL after HSCT $(10,12)$ the therapies inhibiting immune checkpoints (13). Moreover, the success of monoclonal antibody therapies including e.g., Rituximab depends on NK cell-mediated antibody dependent cytotoxicity (ADCC) as a main effector function (14). Lastly, there are many studies evaluating the therapeutic value of expanded NK cells or therapies with engineered NK cells or T cells (15-18).

Platelets have a well-established and important role in hemostasis and wound healing, but it has become clear that they also function as immune cells (19). In the context of cancer, they have been shown to support various steps of tumor expansion, including local growth, migration in and out of the blood stream and metastasis establishment. During several of those steps platelets are important for evasion of the immune system (20). The protection from immunosurveillance can be the result of a direct or indirect inhibition of tumor cell engagement by cytotoxic lymphocytes. Here, we review the different ways how platelets can support cancer cells to avoid or disarm lymphocyte cytotoxicity focusing on NK cells. We furthermore explore the possible implications of NK cell platelet-interactions on NK cell therapy and platelet transfusions.

\section{PLATELET-MEDIATED IMMUNE ESCAPE MECHANISMS IN THE TUMOR ENVIRONMENT}

High platelet counts were identified as a risk factor associated with adverse outcome in numerous different tumor entities including lung cancer, breast cancer, ovarian cancer, gastric cancer, pancreas carcinoma, hepato-cellular carcinoma, colon carcinoma, renal cell carcinoma or glioblastoma to name just a few (21-28). Based on these robust data, and studies showing that low lymphocyte counts correlate with shorter survival time (29), the ratio between lymphocytes and platelets has been investigated and identified as a predictive marker for the disease outcome with low platelet-lymphocyte ratios (PLR) favoring a beneficial course of the disease (30-32). Of note, a meta-analysis including 1,340 cancer patients that were treated with an immune checkpoint inhibitor, showed a clear advantage of patients with a low PLR (33). In sum, these observational studies gave rise to the question if platelet count and PLR are mere surrogate markers indicating strong systemic inflammatory response, reflecting advanced progression, or if clinically relevant interactions between platelets and lymphocytes can influence the disease outcome by themselves. Notably, these two explanations are not mutually exclusive. The understanding of how platelets can interfere with the function of different lymphocyte subsets has significantly grown and different mechanisms were uncovered. It was shown that platelets protect tumor cells from different cytotoxic lymphocytes including NK cells and effector T cells. The protective mechanisms from lysis by NK cells can be divided in those resulting from direct interaction including cell contact and cytokine interaction and those involving further cell types (34).

When a single cell or micro metastasis, consisting of a few cells enters the blood stream, it is at the same time leaving the immunosuppressive, protective environment of the tumor. It becomes vulnerable and is more exposed to potential recognition and elimination by the immune system. Metastatic tumor cells that enter the blood can activate platelets by tissue factor (TF)-mediated thrombin generation and the release of ADP or Thromboxane A2 (TXA2) $(35,36)$. The activated platelets can attach to the cancer cells via integrins, fibrin, and Pselectin, forming a layer of platelets, hiding the malignant cell from cellular components of the immune system (37) (Figure 1, left). This "cloaking" of cancer cells with platelets protects them from NK cell-mediated lysis as it was first described in mouse models of metastatic cancers $(38,39)$. Initially, it was hypothesized that the platelets would simply physically shield the cancer cells from direct interaction with the NK cells. More recent research on solid tumor-derived cancer cells showed that there are several more specific mechanisms by which the adherent platelets inhibit activation of NK cells. Adherent platelets can transfer their ligands for inhibitory NK cell receptors to the cancer cell surface, namely HLA class I (40), glucocorticoid-induced TNF-related protein (GITR) ligand (41), and the receptor activator of NFKB (RANK) ligand (42) (Figure 1, right). While KIRs, the receptors for HLA class I, are constitutively expressed on the majority of circulating NK cells, the latter two inhibitory receptors are only up-regulated under certain circumstances. GITR is expressed at low levels in resting NK cells from healthy donors but is up-regulated after activation through IL-2 or IL-15 (43). RANK expression is also absent on resting NK cells from healthy donors but is found on NK cells from patients with AML (44), breast cancer, and colon cancer (42). A recent report suggested that plateletderived PD-L1 could protect PD-L1-negative solid tumors from elimination by $\mathrm{T}$ cells (45), a mechanism that extends also to NK cells (46). In addition, adherent platelets can promote the shedding of the NKG2D ligands MICA and MICB from the cancer cell surface through ADAM10/17-mediated cleavage (47, 48) (Figure 1, right). It has also been shown that platelet-coated tumor cells have less detectable CD112 and CD155 on their surface, the ligands to the activating NK cell receptor DNAM-1 


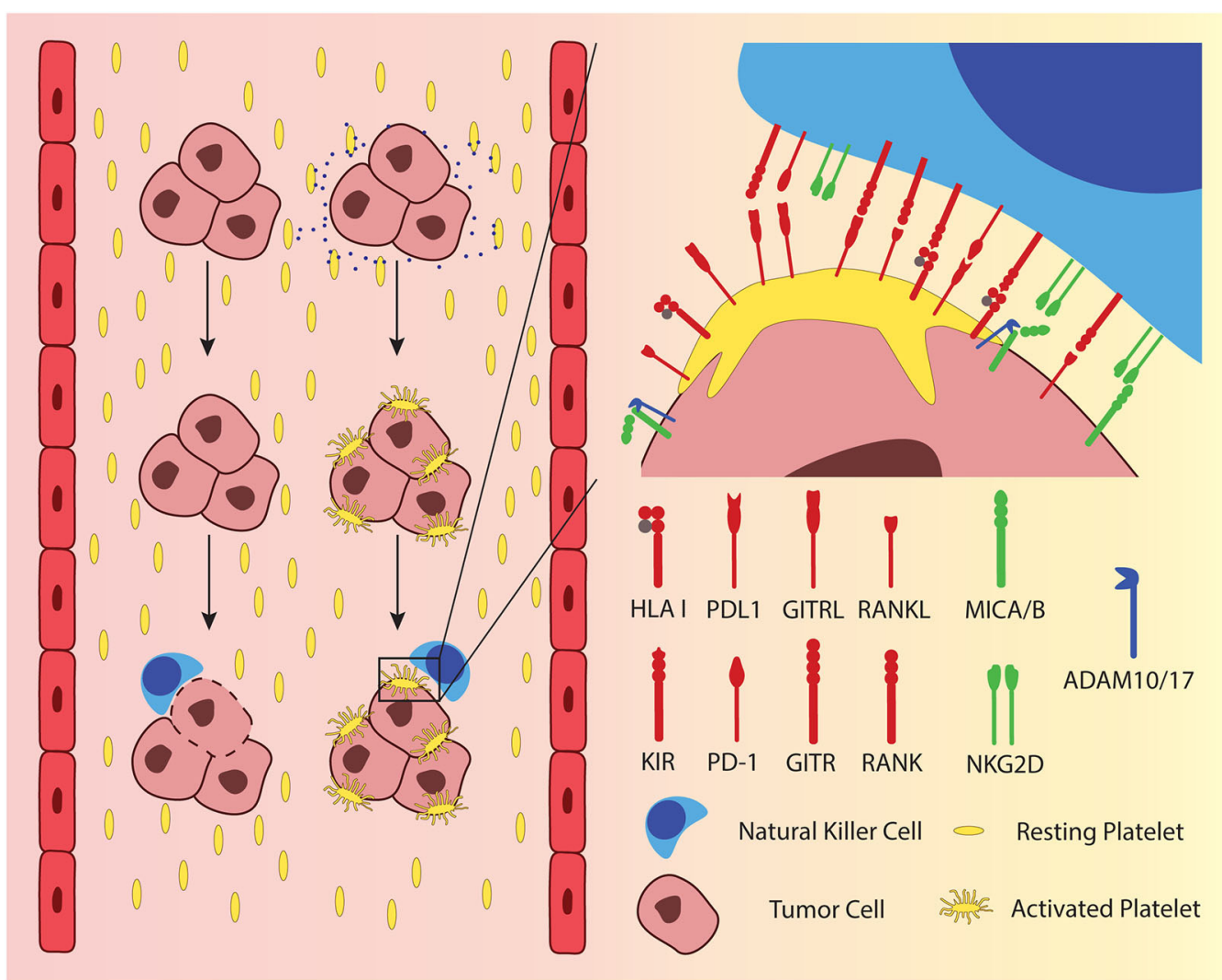

FIGURE 1 | Metastasizing tumor cells exploit platelets as physical and immunological shielding from NK cells in peripheral blood. Platelets are activated upon encountering tumor cells, which release adenosine diphosphate (ADP) and tissue factor (TF), depicted as blue dots. Activated platelets adhere to the tumor cells surface, providing a physical and an immunological shield by presenting ligands to inhibitory NK cell receptors. Moreover, activated platelets exchange surface receptors with tumor cells. Several ligands to inhibitory NK cell receptors have been shown to be passed over from platelets to tumor cells, including HLA class I, glucocorticoid-induced TNF-related protein (GITR) ligand, receptor activator of NFKB (RANK) ligand and PD-L1. The figure furthermore delineates the shedding of MICA and MICB, which are ligands to the activating NK cell receptor NKG2D.

(48). If the mechanism of this reduction involves the interaction of platelet DNAM-1 with its ligands on the cancer cells was not investigated.

The "cloaking" of cancer cells by platelets has mostly been studied in the context of solid tumor metastasis. However, it is very likely to play a role in hematological malignancies, too. Platelets attach to leukocytes in the circulation of healthy donors (49) and have been shown to adhere to the erythroleukemia cell line K562 (48), as well as primary acute myelogenous leukemia (AML) cells in vitro (50). Shedding of NKG2D ligands was observed when platelets attached to K562 cells, similar to cell lines derived from solid tumors (48). Hematological malignancies are often accompanied by thrombocytopenia or platelet dysfunction, a fact that makes platelets appear less likely to play a significant role in the immune evasion of these cancer types, which can explain why the interactions of platelets with hematological cancer cells have been less well-studied. However, in a small study, platelets were found attached to circulating AML blast in three out of eight patients (50) and a study with cryopreserved material from over 1,000 AML patients found platelets adherent to AML blasts in about one third of the cases (51). It appears therefore plausible that leukemia cells may benefit from adhering platelets in a similar way as metastasizing cells from solid tumors do. In consequence, those leukemia cells might be more difficult to target by host immunity, monoclonal antibodies or cellular immunotherapies.

Beside the direct contact-dependent tumor cloaking, platelets can support tumor growth and metastasis through the secretion of various factors (Figure 2). The granules released by platelets upon activation contain amongst others several factors of the coagulation cascade, growth factors and cytokines including TGF- $\beta$ (52). Platelets are, in fact, the main source of TGF- $\beta$ in the human body, both systemically and also specifically in the tumor microenvironment (53-56). TGF- $\beta$ figures among the most extensively investigated immunosuppressive cytokines in the tumor microenvironment and it has been demonstrated to exert deleterious effects by affecting different lymphocytes. TGF$\beta$ inhibits the differentiation of T cells into cytotoxic T cells and raises the number of regulatory $\mathrm{T}$ cells (Tregs) (57-59). Tregs in turn can inhibit effector T cells and NK cells. TGF- $\beta$ also exerts direct impact on NK cells: It has been shown that TGF- $\beta$ 


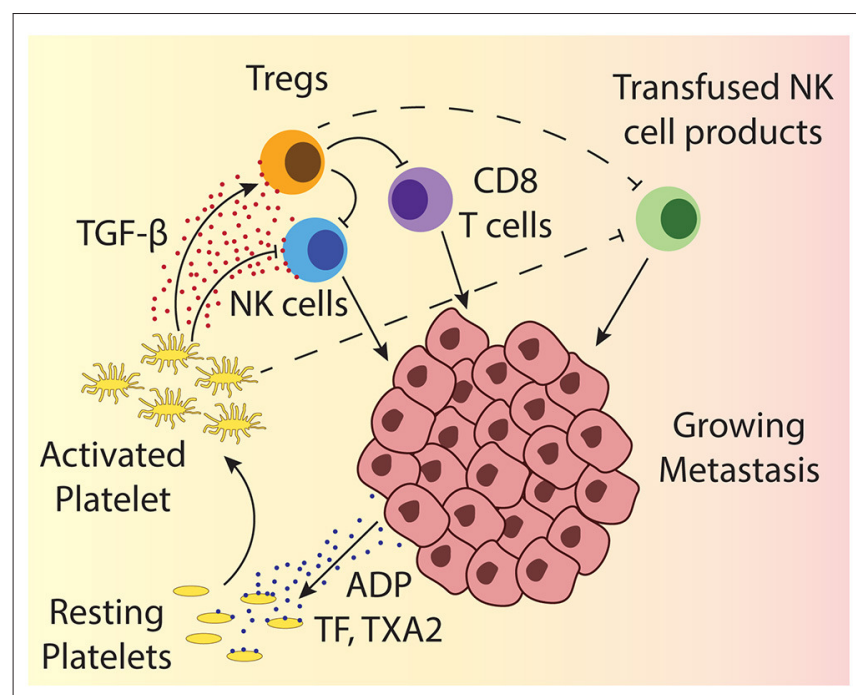

FIGURE 2 | Depicted is a growing metastasis, highlighting the interactions between platelets and different lymphocytes. Tumor cells can activate platelets through release of ADP and TF. ADP directly activates platelets through engagement of the ADP receptor, while TF activates platelets together with other coagulation factors. Platelet activation results in the release of the dense granules and $\alpha$-granules that contain amongst others more ADP, different clotting factors, growth factors, and TGF- $\beta$, which can impact different tumor infiltrating lymphocytes. The impact of TGF- $\beta$ on T cells and NK cells is indicated by solid line arrows and the suspected impact on transfused cellular therapy products is shown by dashed line arrows.

impairs the lytic activity as well as IFN- $\gamma$ production $(60,61)$. The mechanisms how TGF- $\beta$ reduces NK cell activity encompass downregulation of activating receptors on NK cells as e.g., NKp30 or NKG2D, resulting in decreased capability to kill target cells with the respective ligands $(55,62)$ and interference with IFN- $\gamma$ transcription (63). Importantly and beside the fact that platelets are the main source of TGF- $\beta$ it has been specifically proven that platelet-derived TGF- $\beta$ can impair cytokine production and degranulation of NK cells $(55,64)$. Taken together, the TGF- $\beta$ provided by platelets can restrain cellular immune responses in solid tumors, as well as in the bone marrow microenvironment of hematological malignancies and thus support the survival of cancer cells.

\section{DISCUSSION}

Beside the physiological role of NK cells in the control of transformed or virally infected cells, they are also a cornerstone of monoclonal antibody therapies as a mediator of ADCC $(14,65)$. In addition, NK cells exert, beside $\mathrm{T}$ cells, graft vs. tumor effects in allogeneic HSCT settings $(10,15)$ and various cellular therapy approaches based on ex vivo activated or expanded NK cells are pursued (18). In all these settings, it is a common goal to maximize cytotoxicity to achieve tumor eradication. While it remains so far elusive if and to which extent the killing capacity of cellular therapy products are reduced by platelets in the tumor microenvironment, we extrapolate that the infused cellular therapies are likewise inhibited by platelets. Therefore, it is necessary to assess the impact of tumor PLT interactions on cytotoxicity of cellular therapy products. Similar considerations apply to further immunotherapies, that rely on tumor cell lysis mediated by other cytotoxic lymphocytes, especially the inhibition of checkpoints for $\mathrm{T}$ cell activation e.g., by anti-CTLA4, anti-PD1 or antiPDL1 antibodies, as well as therapies with engineered T cells. An increasing number of different immunotherapies which rely on NK cell and other lymphocyte-mediated effector functions find already broad application or have the perspective of doing so $(18,66)$. With a growing understanding of the adverse effects of tumor cell-platelet interactions and the consequences on various lymphocytes, new questions arise. Starting from practical questions; a large portion of patients with hematological malignancies e.g., receive frequent infusions of platelet products (67). Regarding the immunosuppressive potential of platelets described above, an optimization of the transfusion management might be worth considering if the patient is in need of both platelets and cellular therapy at the same time, especially as platelet storage increases the available TGF- $\beta$ in the transfusion unit (64). Beyond this, it is highly desirable to find a generally applicable approach to prevent the adverse interactions between platelets and NK cells. This may also be beneficial for cancer patients regardless if they receive immunotherapy. While it was previously not the scope to target interactions between platelets and NK cells specifically, different approaches were evaluated either aiming to reduce the number of platelets in the tumor microenvironment or to prevent the activation of platelets or their interaction with tumor cells: It was shown that a specific inhibition of tumor-associated platelets by directing the platelet inhibitor ticagrelor to tumor-associated platelets, using a tumor homing liposomal nanoparticle strongly reduced lung metastases in a mammary carcinoma mouse model (68). Another recent study investigated the possibility of targeting cancer cell TF expression with nanoparticle-mediated delivery of siRNA to the site of metastasis in a breast cancer mouse model. This led to a tumor specific silencing of tissue factor, which in turn resulted in reduced platelet adhesion and ultimately in lower numbers of lung metastases (69). Similar observations were made studying the impact of systemic ticagrelor treatment in a breast cancer mouse model (70). However, while NK cell-mediated killing of $\mathrm{K} 562$ in vitro was inhibited in the presence of platelets, no difference was observed if the platelets were pre-treated with ticagrelor or not (71). A very recent study in mice showed reduced metastasis and a reversal of TGF- $\beta$ mediated immunosuppression upon delivery of NOreleasing nanoparticles. The NO released, inhibited platelet activation and therefore TGF- $\beta$ release specifically in the tumor microenvironment (72). A limitation that all approaches targeting the platelet activation share, is that the desired interruption of tumor platelet interaction with tumor cells comes with the risk of reduced coagulation function of platelets. Inhibiting platelet activation is therefore likely unsuitable for thrombocytopenic patients but might be a promising therapy for patients with normal thrombocyte counts, especially when the delivery of the platelet inhibitor can be targeted to the tumor 
microenvironment and unspecific coagulation inhibition can be further reduced.

\section{CONCLUSION}

As platelets can protect cancer cells from cytotoxic lymphocytes by various mechanisms, it is very suggestive that they have an impact on the efficiency of cancer immunotherapies. So far, most studies have investigated either immunotherapy or inhibition of platelet activation, but not the combination of both. Future research will show if targeting the protective interaction of platelets with tumor cells can improve the efficiency of NK cell therapy in solid tumors where results so far were less promising than in immunotherapy of hematological malignancies. On the other hand, in hematological malignancies that are often accompanied by thrombocytopenia, it is less likely that inhibition of platelet activation would be beneficial for the patients. Here, however, the effects of platelets on NK cell cytotoxicity should be considered in the scheduling of platelet transfusions and treatment.

\section{REFERENCES}

1. Cooper MA, Fehniger TA, Caligiuri MA. The biology of human natural killer-cell subsets. Trends Immunol. (2001) 22:633-40. doi: 10.1016/S1471-4906(01)02060-9

2. Timonen T, Saksela E. Isolation of human NK cells by density gradient centrifugation. J Immunol Methods. (1980) 36:28591. doi: 10.1016/0022-1759(80)90133-7

3. Ljunggren HG, Karre K. In search of the 'missing self': MHC molecules and NK cell recognition. Immunol Today. (1990) 11:237-44. doi: 10.1016/0167-5699(90)90097-S

4. Alter G, Malenfant JM, Altfeld M. CD107a as a functional marker for the identification of natural killer cell activity. J Immunol Methods. (2004) 294:1522. doi: 10.1016/j.jim.2004.08.008

5. Watzl C. How to trigger a killer: modulation of natural killer cell reactivity on many levels. Adv Immunol. (2014) 124:13770. doi: 10.1016/B978-0-12-800147-9.00005-4

6. Raulet DH, Gasser S, Gowen BG, Deng W, Jung H. Regulation of ligands for the NKG2D activating receptor. Annu Rev Immunol. (2013) 31:41341. doi: 10.1146/annurev-immunol-032712-095951

7. Biassoni R, Cantoni C, Pende D, Sivori S, Parolini S, Vitale M, et al. Human natural killer cell receptors and co-receptors. Immunol Rev. (2001) 181:20314. doi: 10.1034/j.1600-065X.2001.1810117.x

8. Orange JS. Natural killer cell deficiency. J Allergy Clin Immunol. (2013) 132:515-25. doi: 10.1016/j.jaci.2013.07.020

9. Yokoyama WM, Scalzo AA. Natural killer cell activation receptors in innate immunity to infection. Microbes Infect. (2002) 4:1513-21. doi: 10.1016/S1286-4579(02)00034-5

10. Ruggeri L, Capanni M, Casucci M, Volpi I, Tosti A, Perruccio $\mathrm{K}$, et al. Role of natural killer cell alloreactivity in HLAmismatched hematopoietic stem cell transplantation. Blood. (1999) 94:333-9. doi: 10.1182/blood.V94.1.333.413a31_333_339

11. Becker PS, Suck G, Nowakowska P, Ullrich E, Seifried E, Bader P, et al. Selection and expansion of natural killer cells for NK cellbased immunotherapy. Cancer Immunol Immunother. (2016) 65:47784. doi: 10.1007/s00262-016-1792-y

12. Kolb HJ. Graft-versus-leukemia effects of transplantation and donor lymphocytes. Blood. (2008) 112:4371-83. doi: 10.1182/blood-2008-03-077974

13. Pesce S, Trabanelli S, Di Vito C, Greppi M, Obino V, Guolo F, et al. Cancer immunotherapy by blocking immune checkpoints on innate lymphocytes. Cancers. (2020) 12:3504. doi: 10.3390/cancers12123504

\section{AUTHOR CONTRIBUTIONS}

LS, PH, and SM wrote the manuscript. All authors contributed to the article and approved the submitted version.

\section{FUNDING}

This study was supported by grants to PH from the Swedish Cancer Society (2018/689), Radiumhemmets Forskningsfonder (181133), Cancer och Allergifonden, Aroseniusfonden, the Karolinska Institute Strategic Research Area in Stem Cells and Regenerative Medicine, and the Stockholm City Council (20170287). LS was supported from the Swiss National Science Foundation (SNF): P400PM_183909 to LS.

\section{ACKNOWLEDGMENTS}

We thank all members of the $\mathrm{PH}$ group at HERM for fruitful discussions.

14. Terszowski G, Klein C, Schmied L, Stern M. How to outsmart NK cell tolerance. Oncoimmunology. (2015) 4:e1016708. doi: 10.1080/2162402X.2015.1016708

15. Ruggeri L, Mancusi A, Capanni M, Urbani E, Carotti A, Aloisi $\mathrm{T}$, et al. Donor natural killer cell allorecognition of missing self in haploidentical hematopoietic transplantation for acute myeloid leukemia: challenging its predictive value. Blood. (2007) 110:433-40. doi: 10.1182/blood-2006-07-038687

16. Shimasaki N, Jain A, Campana D. NK cells for cancer immunotherapy. Nat Rev Drug Discov. (2020) 19:200-18. doi: 10.1038/s41573-019-0052-1

17. June CH, O'Connor RS, Kawalekar OU, Ghassemi S, Milone MC. CAR $\mathrm{T}$ cell immunotherapy for human cancer. Science. (2018) 359:13615. doi: 10.1126/science.aar6711

18. Myers JA, Miller JS. Exploring the NK cell platform for cancer immunotherapy. Nat Rev Clin Oncol. (2021) 18:85100. doi: 10.1038/s41571-020-0426-7

19. Maouia A, Rebetz J, Kapur R, Semple JW. The immune nature of platelets revisited. Transfus Med Rev. (2020) 34:20920. doi: 10.1016/j.tmrv.2020.09.005

20. Goubran HA, Stakiw J, Radosevic M, Burnouf T. Platelets effects on tumor growth. Semin Oncol. (2014) 41:35969. doi: 10.1053 /j.seminoncol.2014.04.006

21. Lu L, Su Z, Zheng P, Wu Z, Zhang Y, He H, et al. Association between platelet count and hepatocellular carcinoma overall survival: a large retrospective cohort study. BMJ Open. (2020) 10:e038172. doi: 10.1136/bmjopen-2020-038172

22. Yang $C$, Jiang $H$, Huang $S$, Hong $H$, Huang $X$, Wang $X$, et al. The prognostic role of pretreatment thrombocytosis in gastric cancer: a systematic review and meta-analysis. Medicine. (2018) 97:e11763. doi: 10.1097/MD.0000000000011763

23. Taucher S, Salat A, Gnant M, Kwasny W, Mlineritsch B, Menzel RC, et al. Impact of pretreatment thrombocytosis on survival in primary breast cancer. Thromb Haemost. (2003) 89:1098-106. doi: 10.1055/s-00371613413

24. Brown KM, Domin C, Aranha GV, Yong S, Shoup M. Increased preoperative platelet count is associated with decreased survival after resection for adenocarcinoma of the pancreas. Am J Surg. (2005) 189:27882. doi: 10.1016/j.amjsurg.2004.11.014

25. Brockmann MA, Giese A, Mueller K, Kaba FJ, Lohr F, Weiss C, et al. Preoperative thrombocytosis predicts poor survival in patients with glioblastoma. Neuro Oncol. (2007) 9:335-42. doi: 10.1215/15228517-2007-013 
26. Costantini V, Zacharski LR, Moritz TE, Edwards RL. The platelet count in carcinoma of the lung and colon. Thromb Haemost. (1990) 64:5015. doi: 10.1055/s-0038-1647347

27. Inoue K, Kohashikawa K, Suzuki S, Shimada M, Yoshida H. Prognostic significance of thrombocytosis in renal cell carcinoma patients. Int J Urol. (2004) 11:364-7. doi: 10.1111/j.1442-2042.2004.00808.x

28. Menczer J, Schejter E, Geva D, Ginath S, Zakut H. Ovarian carcinoma associated thrombocytosis. Correlation with prognostic factors and with survival. Eur J Gynaecol Oncol. (1998) 19:82-4.

29. Vigano A, Bruera E, Jhangri GS, Newman SC, Fields AL, Suarez-Almazor ME. Clinical survival predictors in patients with advanced cancer. Arch Intern Med. (2000) 160:861-8. doi: 10.1001/archinte.160.6.861

30. Kim R, Kawai A, Wakisaka M, Sawada S, Shimoyama M, Yasuda N, et al. Immune factors associated with the pathological and therapeutic effects of preoperative chemotherapy in patients with breast cancer. Transl Oncol. (2020) 14:100927. doi: 10.1016/j.tranon.2020.100927

31. Riauka R, Ignatavicius P, Barauskas G. Preoperative platelet to lymphocyte ratio as a prognostic factor for resectable pancreatic cancer: a systematic review and meta-analysis. Dig Surg. (2020) 37:447-55. doi: 10.1159/000508444

32. Cao $\mathrm{W}$, Yao $\mathrm{X}$, Cen $\mathrm{D}$, Zhi $\mathrm{Y}$, Zhu $\mathrm{N}, \mathrm{Xu} \mathrm{L}$. The prognostic role of platelet-to-lymphocyte ratio on overall survival in gastric cancer: a systematic review and meta-analysis. BMC Gastroenterol. (2020) 20:16. doi: 10.1186/s12876-020-1167-x

33. Xu H, He A, Liu A, Tong W, Cao D. Evaluation of the prognostic role of platelet-lymphocyte ratio in cancer patients treated with immune checkpoint inhibitors: a systematic review and meta-analysis. Int Immunopharmacol. (2019) 77:105957. doi: 10.1016/j.intimp.2019.105957

34. Quail DF, Joyce JA. Microenvironmental regulation of tumor progression and metastasis. Nat Med. (2013) 19:1423-37. doi: 10.1038/nm.3394

35. Zara M, Canobbio I, Visconte C, Canino J, Torti M, Guidetti GF. Molecular mechanisms of platelet activation and aggregation induced by breast cancer cells. Cell Signal. (2018) 48:45-53. doi: 10.1016/j.cellsig.2018.04.008

36. Nie D, Che M, Zacharek A, Qiao Y, Li L, Li X, et al. Differential expression of thromboxane synthase in prostate carcinoma: role in tumor cell motility. Am J Pathol. (2004) 164:429-39. doi: 10.1016/S0002-9440(10)63133-1

37. Amo L, Tamayo-Orbegozo E, Maruri N, Eguizabal C, Zenarruzabeitia O, Rinon $\mathrm{M}$, et al. Involvement of platelet-tumor cell interaction in immune evasion. Potential role of podocalyxin-like protein 1. Front Oncol. (2014) 4:245. doi: $10.3389 /$ fonc. 2014.00245

38. Nieswandt B, Hafner M, Echtenacher B, Mannel DN. Lysis of tumor cells by natural killer cells in mice is impeded by platelets. Cancer Res. (1999) 59:1295300.

39. Palumbo JS, Talmage KE, Massari JV, La Jeunesse CM, Flick MJ, Kombrinck KW, et al. Platelets and fibrin(ogen) increase metastatic potential by impeding natural killer cell-mediated elimination of tumor cells. Blood. (2005) 105:17885. doi: 10.1182/blood-2004-06-2272

40. Placke T, Orgel M, Schaller M, Jung G, Rammensee HG, Kopp HG, et al. Platelet-derived MHC class I confers a pseudonormal phenotype to cancer cells that subverts the antitumor reactivity of natural killer immune cells. Cancer Res. (2012) 72:440-8. doi: 10.1158/0008-5472.CAN-11-1872

41. Placke T, Salih HR, Kopp HG. GITR ligand provided by thrombopoietic cells inhibits NK cell antitumor activity. J Immunol. (2012) 189:15460. doi: 10.4049/jimmunol.1103194

42. Clar KL, Hinterleitner C, Schneider P, Salih HR, Maurer S. Inhibition of NK reactivity against solid tumors by platelet-derived RANKL. Cancers. (2019) 11:277. doi: 10.3390/cancers11030277

43. Baltz KM, Krusch M, Bringmann A, Brossart P, Mayer F, Kloss M, et al. Cancer immunoediting by GITR (glucocorticoid-induced TNF-related protein) ligand in humans: NK cell/tumor cell interactions. FASEB J. (2007) 21:2442-54. doi: 10.1096/fj.06-7724com

44. Schmiedel BJ, Nuebling T, Steinbacher J, Malinovska A, Wende CM, Azuma $\mathrm{M}$, et al. Receptor activator for NF-kappaB ligand in acute myeloid leukemia: expression, function, and modulation of NK cell immunosurveillance. $J$ Immunol. (2013) 190:821-31. doi: 10.4049/jimmunol.1201792

45. Zaslavsky AB, Adams MP, Cao X, Maj T, Choi JE, Stangl-Kremser J, et al. Platelet PD-L1 suppresses anti-cancer immune cell activity in PDL1 negative tumors. Sci Rep. (2020) 10:19296. doi: 10.1038/s41598-020-76 351-4
46. Pesce S, Greppi M, Grossi F, Del Zotto G, Moretta L, Sivori S, et al. PD/1-PDLs checkpoint: insight on the potential role of NK cells. Front Immunol. (2019) 10:1242. doi: 10.3389/fimmu.2019.01242

47. Maurer S, Kropp KN, Klein G, Steinle A, Haen SP, Walz JS, et al. Platelet-mediated shedding of NKG2D ligands impairs NK cell immune-surveillance of tumor cells. Oncoimmunology. (2018) 7:e1364827. doi: 10.1080/2162402X.2017.1364827

48. Cluxton CD, Spillane C, O'Toole SA, Sheils O, Gardiner CM, O'Leary JJ. Suppression of natural killer cell NKG2D and CD226 anti-tumour cascades by platelet cloaked cancer cells: implications for the metastatic cascade. PLoS ONE. (2019) 14:e0211538. doi: 10.1371/journal.pone.0211538

49. Li N, Hu H, Lindqvist M, Wikstrom-Jonsson E, Goodall AH, Hjemdahl P. Platelet-leukocyte cross talk in whole blood. Arterioscler Thromb Vasc Biol. (2000) 20:2702-8. doi: 10.1161/01.ATV.20.12.2702

50. Foss B, Ulvestad E, Hervig T, Bruserud O. Effects of cytarabine and various anthracyclins on platelet activation: characterization of in vitro effects and their possible clinical relevance in acute myelogenous leukemia. Int J Cancer. (2002) 97:106-14. doi: 10.1002/ijc.1566

51. Betz SA, Foucar K, Head DR, Chen IM, Willman CL. False-positive flow cytometric platelet glycoprotein IIb/IIIa expression in myeloid leukemias secondary to platelet adherence to blasts. Blood. (1992) 79:2399403. doi: 10.1182/blood.V79.9.2399.2399

52. Whiteheart SW. Platelet granules: surprise packages. Blood. (2011) 118:1190 1. doi: 10.1182/blood-2011-06-359836

53. Rachidi S, Metelli A, Riesenberg B, Wu BX, Nelson MH, Wallace C, et al. Platelets subvert $\mathrm{T}$ cell immunity against cancer via GARP-TGFbeta axis. Sci Immunol. (2017) 2:eaai7911. doi: 10.1126/sciimmunol.aai7911

54. Hu Q, Hisamatsu T, Haemmerle M, Cho MS, Pradeep S, Rupaimoole R, et al. Role of platelet-derived Tgfbetal in the progression of ovarian cancer. Clin Cancer Res. (2017) 23:5611-21. doi: 10.1158/1078-0432.CCR-16-3272

55. Kopp HG, Placke T, Salih HR. Platelet-derived transforming growth factor-beta down-regulates NKG2D thereby inhibiting natural killer cell antitumor reactivity. Cancer Res. (2009) 69:7775-83. doi: 10.1158/0008-5472.CAN-09-2123

56. Assoian RK, Komoriya A, Meyers CA, Miller DM, Sporn MB. Transforming growth factor-beta in human platelets. Identification of a major storage site, purification, and characterization. J Biol Chem. (1983) 258:715560. doi: 10.1016/S0021-9258(18)32345-7

57. Gorelik L, Flavell RA. Abrogation of TGFbeta signaling in $\mathrm{T}$ cells leads to spontaneous $\mathrm{T}$ cell differentiation and autoimmune disease. Immunity. (2000) 12:171-81. doi: 10.1016/S1074-7613(00) 80170-3

58. Gorelik L, Flavell RA. Immune-mediated eradication of tumors through the blockade of transforming growth factor-beta signaling in T cells. Nat Med. (2001) 7:1118-22. doi: 10.1038/nm1001-1118

59. Flavell RA, Sanjabi S, Wrzesinski SH, Licona-Limon P. The polarization of immune cells in the tumour environment by TGFbeta. Nat Rev Immunol. (2010) 10:554-67. doi: 10.1038/nri2808

60. Laouar Y, Sutterwala FS, Gorelik L, Flavell RA. Transforming growth factor-beta controls $\mathrm{T}$ helper type 1 cell development through regulation of natural killer cell interferon-gamma. Nat Immunol. (2005) 6:6007. doi: 10.1038/ni1197

61. Rook AH, Kehrl JH, Wakefield LM, Roberts AB, Sporn MB, Burlington $\mathrm{DB}$, et al. Effects of transforming growth factor beta on the functions of natural killer cells: depressed cytolytic activity and blunting of interferon responsiveness. J Immunol. (1986) 136:3916-20.

62. Castriconi R, Cantoni C, Della Chiesa M, Vitale M, Marcenaro E, Conte $\mathrm{R}$, et al. Transforming growth factor beta 1 inhibits expression of NKp30 and NKG2D receptors: consequences for the NK-mediated killing of dendritic cells. Proc Natl Acad Sci USA. (2003) 100:41205. doi: 10.1073/pnas.0730640100

63. Trotta R, Dal Col J, Yu J, Ciarlariello D, Thomas B, Zhang X, et al. TGFbeta utilizes SMAD3 to inhibit CD16-mediated IFN-gamma production and antibody-dependent cellular cytotoxicity in human NK cells. J Immunol. (2008) 181:3784-92. doi: 10.4049/jimmunol.181.6.3784

64. Sadallah S, Schmied L, Eken C, Charoudeh HN, Amicarella F, Schifferli JA. Platelet-derived ectosomes reduce NK cell function. J Immunol. (2016) 197:1663-71. doi: 10.4049/jimmunol.1502658 
65. Terszowski G, Klein C, Stern M. KIR/HLA interactions negatively affect rituximab- but not GA101 (obinutuzumab)-induced antibody-dependent cellular cytotoxicity. J Immunol. (2014) 192:5618-24. doi: 10.1158/1538-7445.AM2014-650

66. Brudno JN, Kochenderfer JN. Recent advances in CAR T-cell toxicity: mechanisms, manifestations and management. Blood Rev. (2019) 34:4555. doi: 10.1016/j.blre.2018.11.002

67. Estcourt LJ, Stanworth SJ, Harrison P, Powter G, McClure M, Murphy MF, et al. Prospective observational cohort study of the association between thromboelastometry, coagulation and platelet parameters and bleeding in patients with haematological malignancies- the ATHENA study. Br J Haematol. (2014) 166:581-91. doi: 10.1111/bjh. 12928

68. Zhang Y, Wei J, Liu S, Wang J, Han X, Qin H, et al. Inhibition of platelet function using liposomal nanoparticles blocks tumor metastasis. Theranostics. (2017) 7:1062-71. doi: 10.7150/thno.17908

69. Liu S, Zhang Y, Zhao X, Wang J, Di C, Zhao Y, et al. Tumorspecific silencing of tissue factor suppresses metastasis and prevents cancer-associated hypercoagulability. Nano Lett. (2019) 19:4721-30. doi: 10.1021/acs.nanolett.9b01785

70. Gebremeskel S, LeVatte T, Liwski RS, Johnston B, Bezuhly M. The reversible P2Y12 inhibitor ticagrelor inhibits metastasis and improves survival in mouse models of cancer. Int J Cancer. (2015) 136:234-40. doi: 10.1002/ijc. 28947

71. Gareau AJ, Brien C, Gebremeskel S, Liwski RS, Johnston B, Bezuhly M. Ticagrelor inhibits platelet-tumor cell interactions and metastasis in human and murine breast cancer. Clin Exp Metastasis. (2018) 35:2535. doi: 10.1007/s10585-018-9874-1

72. Xu Y, Liu J, Liu Z, Ren H, Yong J, Li W, et al. Blockade of platelets using tumor-specific NO-releasing nanoparticles prevents tumor metastasis and reverses tumor immunosuppression. ACS Nano. (2020) 14:978095. doi: 10.1021/acsnano.0c01687

Conflict of Interest: The authors declare that the research was conducted in the absence of any commercial or financial relationships that could be construed as a potential conflict of interest.

Copyright (c) 2021 Schmied, Höglund and Meinke. This is an open-access article distributed under the terms of the Creative Commons Attribution License (CC BY). The use, distribution or reproduction in other forums is permitted, provided the original author(s) and the copyright owner(s) are credited and that the original publication in this journal is cited, in accordance with accepted academic practice. No use, distribution or reproduction is permitted which does not comply with these terms. 